\title{
AMINO ACID COMPOSITION OF COTTONSEED AS RELATED TO HORIZONTAL AND VERTICAL RESISTANCE TO FUSARIUM WILT DISEASE
}

\author{
Aly, A. A. ${ }^{1}$; M. G. M. El-Samman ${ }^{2}$; M. R. Omar ${ }^{1}$, and \\ A.M.A. El-Samawaty ${ }^{1}$ \\ 1 Plant Pathology Research Institute, Agric. Res. Center, Giza, Egypt. \\ 2 Dept. of Plant Path., Faculty of Agric., Ain Shams Univ., Shoubra El- \\ Kheima, Cairo, Egypt.
}

\begin{abstract}
Four isolates of Fusarium oxysporum f.sp. vasinfectum (FOV) were tested for levels of pathogenicity on 45-day-old greenhouse grown seedlings of 20 cotton genotypes. Isolates differed significantly $(p=0.04)$ in their pathogenicity on the genotypes. Similarly, differences among genotypes were very highly significant $(p=0.0000)$ when they were tested against the isolates. Isolate $x$ genotype interaction was a highly significant $(p=0.01)$ source of variation in wilt incidence suggesting that the genotypes responded differently to the different isolates. These results imply that the pathogenicity of the tested isolates is a mixture of both aggressiveness and virulence and there are significant differences among isolates in both types of pathogenicity. Similarly, resistance of the tested genotypes is also a mixture of both vertical resistance (VR) and horizontal resistance $(\mathrm{HR})$ and the genotypes significantly differ in both types of resistance. Assessment of the relative contribution of each source of variation to the explained (model) variation in wilt incidence revealed that isolate aggressiveness accounted for $0.88 \%$ of the explained variation, $\mathrm{HR}$ of the genotypes accounted for $89.28 \%$, and virulence of the isolates or VR of the genotypes accounted for $8.95 \%$. The GLC analysis of amino acid composition of cottonseeds revealed the presence of 17 amino acids but the occurrence of each in the seeds varied with the genotype. Lysine and glycine were negatively $(r=-0.385)$ and positively $(r=0.418)$ correlated $(p<0.10)$ with VR of the genotypes to $S_{3}$ and $S_{4}$, respectively. None of the other amino acids was significantly correlated with VR of the genotypes to any isolate. Data for VR of the genotypes to each of the tested isolates (dependent variables) and concentrations of the amino acids (independent variables or predictors) were entered into a computerized stepwise multiple regression analysis. Using the predictors supplied by stepwise regression, 4 models were constructed to predict VR of the genotypes to FOV isolates. One of the generated models proved to be effective in prediction VR of the genotypes to $S_{2}$. This model showed that differences in VR to $S_{2}$ among the genotypes were due largely to the amino acids alanine, histedine, lysine, and cystine, which accounted for $61.71 \%$ of the total variation in VR. Concentrations of proline, histedine, and lysine accounted for $36.36 \%$ of the total variation in HR. The findings of the present study suggest that the variations in amino acids may, at least in part, account for the differences in the VR or HR of the different cotton genotypes to FOV.
\end{abstract}

\section{INTRODUCTION}

Fusarium wilt (Fusarium oxysporum. Schelecht f.sp. vasinfectum, (Atk.) Snyd. and Hans.) of cotton (Gossypium spp.) has long been known in the Nile Valley, where it caused serious losses in the commercial Egyptian cottons ( $G$. barbadense L.) in the late fifties (Bakry et al., 1958). Since then, an extensive cotton-breeding program was initiated to develop cultivars 
Aly, A. A. et al.

resistant to the disease. In this program, cotton genotypes are screened under greenhouse conditions, in soil infested with the wilt fungus.

Currently, screening of breeding materials under greenhouse conditions is the only reliable method to distinguish the Fusarium-wilt highly resistant genotypes. The test is time consuming and may be influenced by variability inherent in the experimental system (A.A. Aly, personal observations). The first symptoms of the disease appear on susceptible genotypes after 20 days from planting date under very favorable environmental conditions and may require a longer period of time under less favorable conditions.

Therefore, another reliable method either alternative or complementary to the greenhouse tests, is required for identification of the Fusarium-wilt highly resistant genotypes.

A considerable body of literature has shown a strong relationship between amino acids and diseases caused by Fusarium spp. in particular formae speciales of $F$. oxysporum the incitants of vascular wilt. Amino acids have direct effects on the physiological activities associated with pathogenicity of Fusarium spp. like germination of conidia, elongation of germ tubes, and production and efficiency of enzymes. For instance, Mehta et al. (1991) tested amino acids for the secretion of pectolytic and cellulolytic enzymes. They found complete inhibition of polygalacturonase (PG) synthesis with leucine and phenylalanine in $F$. oxysporum and $F$. moniliforme, respectively. Leucine showed complete inhibition of pectinmethylgalaturonase (PMG) synthesis in $F$. oxysporum. In $F$. moniliforme, cyctine and phenylalanine also inhibited PMG synthesis. Total inhibition of cellulose production was found in $F$. moniliforme by leucine, phenylalanine, and tryptophan whereas none could control the total cellulose synthesis in F. oxysporum. Leaves of 40-day-old healthy and wilted lentils were collected and analyzed for amino acids. The concentration of total free amino acids increased considerably in leaves infected by $F$. oxysporum f.sp. lentils but there were no qualitative changes in free amino acids in infected leaves (Pundir et al., 1991). Frequency and pathogenicity of $F$. oxysporum f.sp. vasinfectum, the Fusarium wilt pathogen on cotton, decreased with increase in years of cropping of resistant cultivars. Root exudates from a resistant cultivar inhibited colony growth and the formation and germination of chlamydospores. This was not the case with exudate from a susceptible cultivar. Spectrophotometric analysis showed that root exudate from the resistant cultivar contained certain amino acids not present in exudate from the susceptible one. These results suggested that build up of root exudates from resistant cultivars in the soil over the years inhibited chlamydospores formation and germination. Thus, reducing pathogen populations (Yang et al., 1995). Mahakul et al. (1996) studied formation and germination of hyphal chlamydospores in $F$. oxysporum f.sp. ciceri, the vascular wilt pathogen on chickpea. In slide germination tests, they found that exudate from a susceptible host cultivar highly stimulated both chlamydospore germination and germ tube growth compared with that from a resistant cultivar. The same was observed when germination on soil was studied. Biochemical analysis indicated the presence of higher levels of amino acids in exudates of the susceptible 
cultivar compared with those in exudates from the resistant cultivar. No appreciable difference in the level of phenolics was detected in the exudates from the two cultivars. Thus, the differential effect of exudates on spore germination was probably not due to the exudation of antifungal compounds, such as phenolics, from the resistant host cultivar, but possibly due to a disparity in the levels of nutrients, such as amino acids, exuded through the roots of the cultivars. Liu (1997) analyzed seedlings of 14 upland cotton varieties at the 3-leaf stage for their amino acid contents. When inoculated with $F$. oxysporum f.sp. vasinfectum, the resistant genotype seedlings had $15-19 \%$ lower total free amino acids and the susceptible genotype seedlings had $13-20 \%$ higher total free amino acids than their respective noninoculated controls. Total amino acids decreased in both resistant and susceptible genotypes.

The objectives of the present study were to (1) evaluate the relationship between vertical and horizontal resistance of cotton to FOV and amino acid composition of seed. (2) develop statistical models to predict vertical and horizontal resistance to FOV by using amino acids in the seed as biochemical predictors.

\section{MATERIALS AND METHODS}

\section{Cotton genotypes:}

Cotton genotypes used in the present study were obtained from Cotton Research Institute, Agri. Res. Cent., Giza.

Isolates of Fusarium oxysporum f.sp. vasinfectum (FOV):

Isolation, purification, and identification to forma specialis level of the isolates (Table 1) used in the present study were carried out at Cotton Pathology Lab., Plant Path. Res. Inst., Agric. Res. Cent., Giza.

Table 1. Geographic origins of Fusarium oxysporum f.sp. vasinfectum (FOV) isolates used in the present study.

\begin{tabular}{lc}
\hline solate no. & Geographic origin \\
\hline $\mathrm{S}_{1}$ & Minya El-Kamh, Sharqiya \\
$\mathrm{S}_{2}$ & Damanhoor, Beheira \\
$\mathrm{S}_{3}$ & Sinbillawain, Daqahliya \\
$\mathrm{S}_{4}$ & Shirbeen, Daqahliya \\
\hline
\end{tabular}

\section{Interaction between cotton genotypes and isolates of FOV:}

Substrate for growth of each isolate was prepared in $500-\mathrm{ml}$ glass bottles contained $50 \mathrm{~g}$ of sorghum grains and $40 \mathrm{ml}$ of tap water. Contents of bottles were autoclaved for 30 minutes. Isolate inoculum, taken from oneweek old culture on PDA, was aseptically introduced into the bottle and allowed to colonize sorghum for 3 weeks. The present test was carried out by using autoclaved clay loam soil. Batches of soil were infested separately with inoculum of each isolate at a rate of $0.5 \mathrm{~g} / \mathrm{kg}$ of soil. Infested soil was dispensed in 10-cm-diameter clay pots and these were planted with seeds of the tested genotypes (10 seeds/pot). In the control treatments, the 
genotypes were grown in autoclaved soil. Pots were randomly distributed on a greenhouse bench under a temperature regime ranged from $23 \pm 3^{\circ} \mathrm{C}$ to $33 \pm 2.5^{\circ} \mathrm{C}$. Percentage of infected seedlings, which showed external or internal symptoms (Aly et al., 2000) were recorded 45 days after planting.

\section{Analysis of amino acid composition of cottonseed:}

Extraction, derivatization, and separation of total amino acid derivatives by GLC were carried out according to Cohen et al., 1989.

\section{Statistical analysis:}

The experimental design of the interaction test was a randomized complete block with five replicates (blocks). Analysis of variance (ANOVA) of the data was performed with MSTAT-C. Least significant difference (LSD) was used to compare genotype means within isolates.

Linear correlation coefficient ( $r$ ) was calculated to evaluate the degree of association between concentration of each amino acid and each of vertical and horizontal resistance of the genotypes. Stepwise regression technique with the greatest increase in $\mathrm{R}^{2}$ as the decision criterion was used to describe the effects of amino acids on each of vertical and horizontal resistance. Correlation and regression analyses were preformed with a computerized program.

\section{RESULTS AND DISCUSSION}

External symptoms of Fusarium wilt were evident in the susceptible seedlings of the tested genotypes 20 days after planting. These seedlings were usually killed within 25 to 30 days after planting or they might survive showing external wilt symptoms on cotyledons. The symptoms were discrete areas of vein discoloration in the cotyledonary leaves, usually began at the margin, turned yellow or brown, eventually, the entire leaf wilted.

A distinctive characteristic of Fusarium wilt is dark brown discoloration of the root and stem xylem. However, there is no consensus of opinions regarding the diagnostic importance of this vascular discoloration for judging susceptibility to Fusarium wilt in a seedling test. For example, Armstrong and Armstrong (1978) stated that vascular discoloration was a questionable standard for judging susceptibility to wilt in a seedling test. Zink et al. (1983) found no clear relationship between the severity of external symptoms in surviving muskmelon seedlings and the extent and degree of internal vascular discoloration. On the other hand, Salgado et al. (1994) used vascular discoloration as a criterion for judging susceptibility of tepary bean seedlings to Fusarium wilt. Osman (1996) found highly significant positive correlation between vascular discoloration of cotton seedlings (cultivar Giza $74)$ and each of wilt incidence $(r=0.93, p<0.01)$ and wilt severity $(r=0.98, p$ $<0.01$ ). In the present study, we used rigorous criteria for disease rating. According to these criteria, the seedlings were considered healthy only if they were completely free of any internal and external symptoms. Thus, the seedlings were considered susceptible if they showed internal discoloration even though they were free of any external symptoms.

Isolates of FOV differed significantly $(p=0.04)$ in their pathogenicity on cotton genotypes. Similarly, differences among cotton genotypes were very 
highly significant $(p=0.0000)$ when they were tested against FOV isolates. Isolate $x$ genotype interaction was a highly significant $(p=0.01)$ suggesting that genotypes responded differently to the different isolates (Table 2 ).

Table 2. Analysis of variance of the interaction between isolates of FOV and cotton genotypes under greenhouse conditions.

\begin{tabular}{lcccc}
\hline Source of variation $^{\text {a }}$ & D.F. & M.S. & F. value & P > F \\
\hline Block & 4 & 574.656 & 2.1678 & 0.0725 \\
Isolate (S) & 3 & 761.548 & 2.8728 & 0.0365 \\
Genotype (G) & 19 & 12151.695 & 45.8404 & 0.0000 \\
S x G & 57 & 405.940 & 1.5313 & 0.0125 \\
Error & 316 & 265.087 & & \\
\hline
\end{tabular}

a Replication is random, while each of isolate and genotype is fixed.

According to Vanderplank (1984), these results imply that the pathogenicity of the tested isolates is a mixture of both aggressiveness and virulence and there are significant differences among isolates in both types of pathogenicity. Similarly, resistance of the tested genotypes is also a mixture of both horizontal and vertical resistance, and the genotypes significantly differ in both types of resistance.

Assessment of the relative contribution of each source of variation to the explained (model) variation in wilt incidence revealed that isolate aggressiveness accounted for $0.88 \%$ of the explained variation, horizontal resistance of genotypes accounted for $89.28 \%$, and virulence of isolates or vertical resistance of the genotypes accounted for $8.95 \%$ (Table 3 ).

Table 3. Relative contribution of FOV isolates, cotton genotypes, and their interaction to variation in wilt incidence.

\begin{tabular}{lc}
\hline Source of variation & Relative contribution ${ }^{\text {a }}$ to variation in wilt incidence \\
\hline Isolate $(\mathrm{S})$ & 0.88 \\
Genotype $(\mathrm{G})$ & 89.28 \\
$\mathrm{~S} \times \mathrm{G}$ & 8.95 \\
\hline a Calculated as percentage of sum of squares of the & 8.95 lained (model) variation
\end{tabular}

a Calculated as percentage of sum of squares of the explained (model) variation.

Taken together, these results indicate that isolate aggressiveness is the least important contributor in determining the variation in wilt incidence. Aggressiveness of isolates is less important than virulence. Horizontal resistance of genotypes is the most important source of variation in wilt incidence and it is much more important than vertical resistance.

Due to the significant interaction between isolates and genotypes, LSD was used to compare between the individual genotype means within isolates, these comparisons showed that the interaction between isolates and genotypes was due to change in the magnitude of the differences between genotypes. For example, the difference between genotype nos. 3 and 4 was significant only within $\mathrm{S}_{4}$, while it was nonsignificant within any of the other isolates. The difference between genotypes nos. 10 and 11 was nonsignificant only within $\mathrm{S}_{2}$ (Table 4). 
Aly, A. A. et al.

Table 4. Wilt incidence ${ }^{\mathrm{a}}$ on cotton genotypes inoculated with isolates of FOV under greenhouse conditions.

\begin{tabular}{|c|c|c|c|c|c|c|c|c|c|c|}
\hline \multirow{3}{*}{ Genotype } & \multicolumn{8}{|c|}{ Isolate } & \multirow{2}{*}{\multicolumn{2}{|c|}{ Mean }} \\
\hline & \multicolumn{2}{|c|}{$S_{1}$} & \multicolumn{2}{|c|}{$\mathrm{S}_{2}$} & \multicolumn{2}{|c|}{$\mathrm{S}_{3}$} & \multicolumn{2}{|c|}{$S_{4}$} & & \\
\hline & $\%$ & $\mathbf{T}^{\mathrm{b}}$ & $\%$ & $\mathbf{T}$ & $\%$ & $\mathbf{T}$ & $\%$ & $\mathbf{T}$ & $\%$ & $\mathbf{T}$ \\
\hline 1 & $2.00^{c}$ & 3.69 & 4.14 & 4.14 & 5.00 & 8.28 & 2.00 & 3.69 & 3.29 & 4.95 \\
\hline 2 & 5.00 & 6.00 & 4.44 & 5.62 & 0.00 & 0.00 & 14.17 & 21.82 & 5.90 & 8.36 \\
\hline 3 & 11.10 & 15.05 & 14.60 & 17.41 & 6.70 & 11.68 & 30.44 & 32.50 & 15.71 & 19.16 \\
\hline 4 & 0.00 & 0.00 & 10.70 & 16.98 & 0.00 & 0.00 & 4.44 & 5.62 & 3.79 & 5.65 \\
\hline 5 & 0.00 & 0.00 & 13.10 & 16.82 & 2.50 & 4.14 & 6.70 & 7.05 & 5.58 & 7.00 \\
\hline 6 & 68.70 & 59.33 & 53.10 & 43.50 & 68.90 & 59.21 & 65.00 & 54.13 & 63.93 & 54.04 \\
\hline 7 & 19.17 & 18.20 & 13.10 & 16.27 & 10.83 & 12.38 & 7.30 & 12.20 & 12.60 & 14.76 \\
\hline 8 & 47.70 & 39.94 & 44.90 & 41.78 & 53.60 & 47.12 & 47.97 & 43.58 & 48.54 & 43.11 \\
\hline 9 & 100.00 & 90.00 & 67.83 & 58.80 & 100.00 & 90.00 & 97.50 & 85.86 & 91.33 & 81.17 \\
\hline 10 & 47.50 & 43.55 & 35.90 & 33.25 & 72.78 & 62.00 & 50.70 & 45.33 & 51.72 & 46.04 \\
\hline 11 & 13.57 & 12.91 & 41.39 & 36.80 & 42.79 & 40.11 & 9.00 & 9.00 & 26.69 & 24.71 \\
\hline 12 & 47.14 & 43.14 & 53.30 & 46.95 & 46.41 & 39.73 & 58.25 & 49.81 & 51.28 & 44.91 \\
\hline 13 & 92.78 & 77.83 & 76.70 & 67.18 & 100.00 & 90.00 & 97.14 & 85.56 & 91.66 & 80.14 \\
\hline 14 & 51.90 & 49.16 & 75.60 & 63.36 & 69.17 & 57.04 & 36.83 & 33.97 & 58.38 & 50.88 \\
\hline 15 & 63.71 & 56.13 & 46.27 & 42.78 & 69.72 & 59.76 & 45.11 & 41.96 & 56.20 & 50.16 \\
\hline 16 & 92.50 & 79.86 & 79.21 & 69.01 & 93.30 & 82.95 & 100.00 & 90.00 & 91.25 & 80.46 \\
\hline 17 & 50.56 & 44.97 & 65.04 & 54.32 & 79.90 & 66.66 & 59.60 & 50.69 & 63.78 & 54.16 \\
\hline 18 & 40.16 & 39.09 & 35.70 & 36.26 & 58.10 & 50.18 & 32.57 & 34.22 & 41.63 & 39.94 \\
\hline 19 & 42.97 & 40.69 & 39.40 & 38.67 & 59.45 & 50.53 & 65.56 & 54.13 & 51.85 & 46.01 \\
\hline Giza 74 & 41.89 & 40.20 & 13.17 & 21.03 & 21.44 & 27.07 & 34.44 & 35.58 & 27.74 & 30.97 \\
\hline Mean & 41.92 & 37.99 & 39.38 & 36.55 & 48.03 & 42.94 & 43.24 & 39.84 & 43.14 & 39.33 \\
\hline $\operatorname{sn}$ & fo & in. & & & 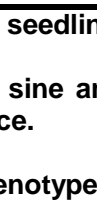 & & & & & \\
\hline
\end{tabular}

The GLC analysis of amino acid composition of cottonseeds revealed the presence of 17 amino acids but the occurrence of each in the seeds varied with the genotype (Table 5).

The relationship between amino acids and resistance to plant diseases is well documented in a large body of literature; however, few attempts have been made to use biometrical approaches to study such a relationship. For instance, El-Hamalawy and Menge (1995) found that the total free amino acid content of the avocado bark tissue was highly correlated with canker size on stem $(r=0.89)$ caused by Phytophthora citricola. Through correlations and path coefficient analysis of a field trial with peas cv. Rachana (resistant) and T163 (susceptible), Bhattacharya abd Shukla (1996) concluded that severity of powdery mildew (Erysiphe polygoni) on field pea is substantially increased by the accumulation of free amino acids. Omokolo et al. (2002) found a significant negative correlation $(r=-65, p<0.05)$ between the level of amino acids in cacao (Theobroma cacao L.) pods and the lesion size caused by $P$. megakarya. Omokolo and Boudjeko (2005) investigated the putative role of amino acids in susceptibility of Xanthosoma sagittifolium to Pythium myriotylum root rot disease by comparing the alteration of amino acids in the roots of the white (susceptible), red (tolerant), and yellow (resistant) cultivars. At day 2 after inoculation, total amino acid content increased in the three 
cultivars. However, this increase was negatively correlated to the disease only in the yellow cultivars $(r=0.94, p<0.05)$.

Table 5. Amino acid composition (\%, w/w) of cottonseed.

\begin{tabular}{ccccccccccc}
\hline Amino & \multicolumn{1}{c}{ Genotype } \\
acid & $\mathbf{1}$ & $\mathbf{2}$ & $\mathbf{3}$ & $\mathbf{4}$ & $\mathbf{5}$ & $\mathbf{6}$ & $\mathbf{7}$ & $\mathbf{8}$ & $\mathbf{9}$ & $\mathbf{1 0}$ \\
\hline Aspartic & $\mathbf{0 . 0 2 9}$ & $\mathbf{0 . 0 3 1}$ & 0.035 & 0.028 & 0.025 & 0.017 & 0.017 & 0.120 & 0.020 & 0.027 \\
Glutamic & $\mathbf{0 . 0 2 8}$ & 0.208 & 0.173 & 0.143 & 0.099 & 0.227 & 0.215 & 0.183 & 0.137 & 0.027 \\
Serine & $\mathbf{0 . 0 2 4}$ & 0.027 & 0.010 & 0.021 & 0.018 & 0.025 & 0.024 & 0.043 & 0.020 & 0.027 \\
Glycine & $\mathbf{0 . 0 3 5}$ & 0.053 & 0.045 & 0.057 & 0.051 & 0.056 & 0.057 & 0.049 & 0.063 & 0.040 \\
Histedine & $\mathbf{0 . 0 1 8}$ & 0.079 & 0.066 & 0.058 & 0.014 & 0.087 & 0.077 & 0.016 & 0.059 & 0.029 \\
Arginine & 0.026 & 0.022 & 0.073 & 0.042 & 0.162 & 0.029 & 0.028 & 0.050 & 0.038 & 0.039 \\
Therionine & $\mathbf{0 . 0 4 7}$ & 0.042 & 0.028 & 0.032 & 0.088 & 0.048 & 0.036 & 0.101 & 0.038 & 0.065 \\
Alanine & $\mathbf{0 . 2 5 5}$ & 0.371 & 0.311 & 0.316 & 0.240 & 0.369 & 0.339 & 0.199 & 0.322 & 0.372 \\
Proline & $\mathbf{0 . 0 5 1}$ & 0.038 & 0.005 & 0.047 & 0.065 & 0.041 & 0.042 & 0.063 & 0.039 & 0.081 \\
Tyrosine & $\mathbf{0 . 0 3 9}$ & 0.043 & 0.040 & 0.070 & 0.071 & 0.043 & 0.038 & 0.009 & 0.054 & 0.075 \\
Valine & 0.040 & 0.040 & 0.001 & 0.046 & 0.037 & 0.041 & 0.039 & 0.064 & 0.040 & 0.052 \\
Methionine & 0.042 & 0.022 & 0.085 & 0.038 & 0.044 & 0.036 & 0.025 & 0.053 & 0.030 & 0.067 \\
Cystine & 0.007 & 0.027 & 0.047 & 0.035 & 0.032 & 0.029 & 0.019 & 0.027 & 0.040 & 0.075 \\
Isoluecine & 0.023 & 0.015 & 0.022 & 0.034 & 0.022 & 0.022 & 0.0 .13 & 0.040 & 0.0221 & 0.051 \\
Luecine & $\mathbf{0 . 0 4 3}$ & 0.060 & 0.034 & 0.061 & 0.043 & 0.065 & 0.057 & 0.077 & 0.055 & 0.070 \\
Phenylalanine & 0.067 & 0.073 & 0.173 & 0.109 & 0.084 & 0.116 & 0.077 & 0.116 & 0.092 & 0.086 \\
Lysine & 0.007 & 0.038 & 0.074 & 0.027 & 0.047 & 0.040 & 0.050 & 0.020 & 0.017 & 0.018 \\
\hline
\end{tabular}

Table 5. (Continued from preceding table).

\begin{tabular}{lcccccccccc}
\hline \multirow{2}{*}{ Amino acid } & $\mathbf{1 1}$ & $\mathbf{1 2}$ & $\mathbf{1 3}$ & $\mathbf{1 4}$ & $\mathbf{1 5}$ & $\mathbf{1 6}$ & $\mathbf{1 7}$ & $\mathbf{1 8}$ & $\mathbf{1 9}$ & $\mathbf{2 0}$ \\
\hline Aspartic & $\mathbf{0 . 1 1 6}$ & $\mathbf{0 . 0 8 9}$ & 0.065 & 0.008 & 0.038 & 0.031 & 0.025 & 0.022 & 0.029 & 0.052 \\
Glutamic & $\mathbf{0 . 0 7 2}$ & 0.039 & 0.034 & 0.024 & 0.229 & 0.125 & 0.161 & 0.157 & 0.077 & 0.153 \\
Serine & $\mathbf{0 . 0 3 7}$ & 0.017 & 0.026 & 0.029 & 0.030 & 0.027 & 0.030 & 0.021 & 0.020 & 0.069 \\
Glycine & $\mathbf{0 . 0 3 7}$ & 0.055 & 0.055 & 0.020 & 0.058 & 0.074 & 0.069 & 0.068 & 0.053 & 0.064 \\
Histedine & $\mathbf{0 . 0 7 7}$ & 0.063 & 0.084 & 0.022 & 0.049 & 0.102 & 0.077 & 0.065 & 0.024 & 0.040 \\
Arginine & 0.079 & 0.041 & 0.106 & 0.068 & 0.163 & 0.031 & 0.036 & 0.030 & 0.040 & 0.054 \\
Therionine & $\mathbf{0 . 0 5 9}$ & 0.109 & 0.057 & 0.035 & 0.099 & 0.076 & 0.045 & 0.034 & 0.103 & 0.087 \\
Alanine & $\mathbf{0 . 3 1 2}$ & 0.217 & 0.297 & 0.158 & 0.255 & 0.217 & 0.322 & 0.235 & 0.262 & 0.372 \\
Proline & $\mathbf{0 . 0 3 5}$ & 0.052 & 0.068 & 0.061 & 0.061 & 0.074 & 0.034 & 0.027 & 0.028 & 0.026 \\
Tyrosine & $\mathbf{0 . 0 6 8}$ & 0.067 & 0.080 & 0.068 & 0.042 & 0.073 & 0.075 & 0.090 & 0.051 & 0.050 \\
Valine & 0.044 & 0.042 & 0.045 & 0.043 & 0.032 & 0.036 & 0.055 & 0.052 & 0.029 & 0.045 \\
Methionine & 0.037 & 0.031 & 0.065 & 0.059 & 0.031 & 0.045 & 0.046 & 0.082 & 0.027 & 0.036 \\
Cystine & 0.052 & 0.034 & 0.036 & 0.039 & 0.009 & 0.020 & 0.037 & 0.012 & 0.008 & 0.010 \\
Isoluecine & 0.037 & 0.034 & 0.025 & $0 . .023$ & 0.017 & 0.034 & 0.026 & 0.025 & 0.011 & 0.025 \\
Luecine & $\mathbf{0 . 0 6 1}$ & 0.047 & 0.034 & 0.054 & 0.068 & 0.041 & 0.065 & 0.045 & 0.052 & 0.063 \\
Phenylalanine & 0.052 & 0.099 & 0.089 & 0.063 & 0.056 & 0.077 & 0.071 & 0.070 & 0.064 & 0.087 \\
Lysine & 0.017 & 0.042 & 0.015 & 0.018 & 0.008 & 0.051 & 0.020 & 0.016 & 0.008 & 0.027 \\
\hline
\end{tabular}

It is well known that the type and degree of association between characters may facilitate or complicate the selection process in breeding programs. Selection for a character may result in an improvement or deterioration in other characters according to the type and degree of correlation. Hence, it was desirable to assess the type and degree of association between resistance of cotton genotypes to FOV and amino acids in cottonseed as biochemical predictors.

Pearson correlation coefficient was calculated to measure the degree of association between vertical resistance (VR) of genotypes to each isolate and 
Aly, A. A. et al.

the concentration (\%) of each separated amino acid (Table 6). Lysine and glycine were negatively and positively correlated $(p<0.10)$ with VR of the genotypes to $S_{3}$ and $S_{4}$, respectively. None of the other amino acids was significantly correlated with VR of the genotypes to any isolate.

Table 6. Correlation between vertical resistance $\left(Y_{s}\right)$ of cotton genotypes to isolates of FOV and amino acid content of the genotype seeds.

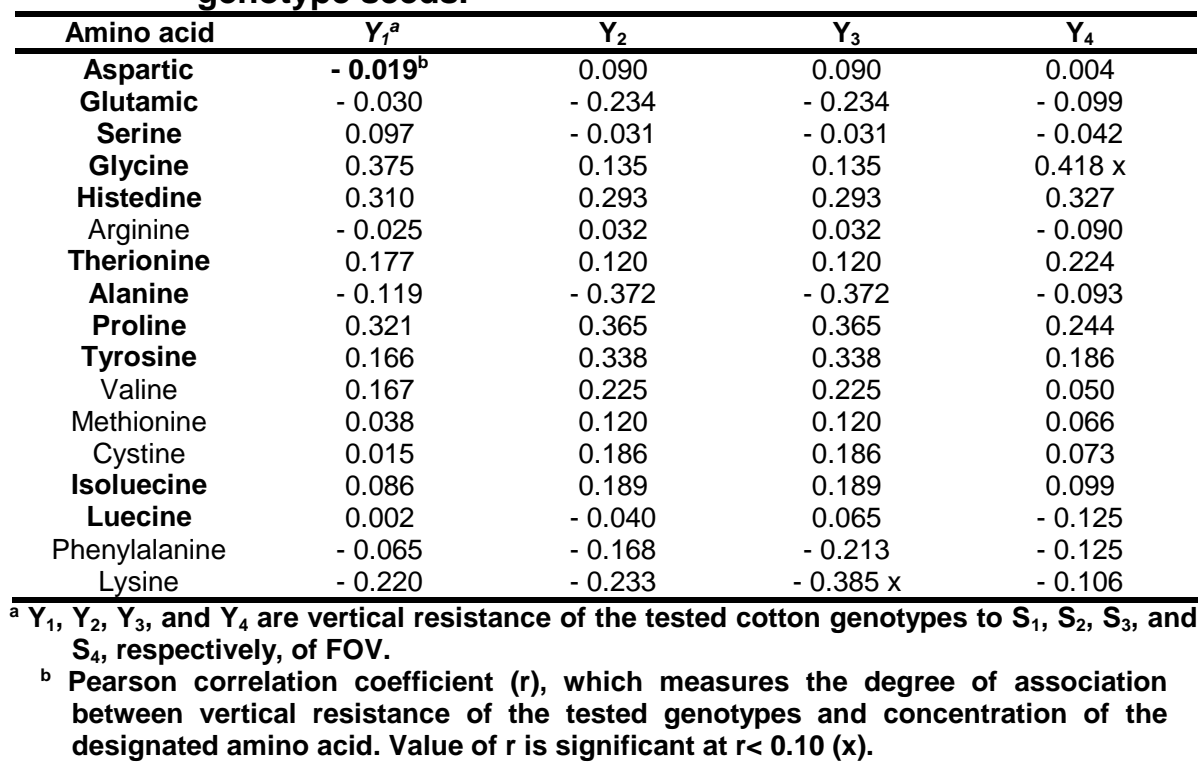

Data for VR of the genotypes to each of the tested isolates and concentrations of amino acids were entered into a computerized stepwise multiple regression analysis. The analysis constructed predictive models by adding predictors, in this case, concentrations of amino acids, to the models in order of their contribution to $\mathrm{R}^{2}$. The analysis was effective in eliminating those amino acids with little or no predictive value by incorporating into the models only those amino acids that made a satisfactory significant contribution to $\mathrm{R}^{2}$ value of the models (Podleckis et al., 1984).

Using the predictors supplied by stepwise regression, 4 models were constructed to predict VR (Table 7). It is noteworthy that the $2^{\text {nd }}$ model was the only one, which can be used reliably to predict VR due to its high $R^{2}$ value. The $R^{2}$ values of the other models were too low to be used for prediction. Despite this limitation, our findings suggest that the variations in amino acids may, at least in part, account for the differences in the VR of the different cotton genotypes to FOV isolates. None of the individual amino acids was satisfactory correlated with horizontal resistance (HR) (Table 8). Concentrations of proline, histedine, and lysine accounted for $36.36 \%$ of the total variation in HR (Table 9). 
Table 7. Stepwise regression models that describe the relationship between vertical resistance $\left(Y_{s}\right)$ of cotton genotypes to four isolates of FOV and amino acid content $\left(X_{s}\right)$ of the genotype seeds.

\begin{tabular}{cccc}
\hline $\begin{array}{c}\text { Isolate of } \\
\text { FOV }\end{array}$ & Stepwise linear regression model & $\begin{array}{c}\text { Coefficient of } \\
\text { determination }\left(\mathbf{R}^{2}\right)\end{array}$ & F. value $^{\mathrm{c}}$ \\
\hline $\mathrm{S}_{1}$ & $\mathrm{Y}_{1}=-44.54+1062.70 \mathbf{X}_{4}+643.70 \mathbf{X}_{9}$ & $28.80 \%^{\mathrm{b}}$ & $3.44 \mathrm{x}$ \\
$\mathrm{S}_{2}$ & $\mathrm{Y}_{2}=80.01-257.94 \mathbf{X}_{8}+631.86 \mathbf{X}_{5}-656.23 \mathbf{X}_{17}+$ & $61.71 \%^{\mathrm{c}}$ & $6.04^{* * *}$ \\
$\mathrm{~S}_{3}$ & $\mathrm{Y}_{3}=10.49-974.94 \mathbf{X}_{17}+645.08 \mathbf{X}_{13}+621.88 \mathbf{X}_{9}$ & $43.61 \%^{\mathrm{d}}$ & $4.12^{*}$ \\
$\mathrm{~S}_{4}$ & $\mathrm{Y}_{3}=16.11+1575.22 \mathbf{X}_{4}-191.68 \mathbf{X}_{2}$ & $31.12 \%^{\mathrm{e}}$ & $3.84^{*}$ \\
\hline
\end{tabular}

a $F$. value is significant at $p<0.10(x), p<0.05\left(^{*}\right)$, or $p<0.005\left(^{(* *}\right)$.

${ }^{b}$ Relative contribution of the predictors $X_{4}$ (Glycine) and $X_{9}$ (Proline) to $R^{2}$ are 14.06 and $14.74 \%$, respectively.

${ }^{c}$ Relative contribution of the predictors $X_{8}$ (Alanine), $X_{5}$ (Histedine), $X_{17}$ (Lysine) and $X_{13}$ (Cystine) to $R^{2}$ are $13.85,20.92,13.82$, and $13.12 \%$, respectively.

${ }^{d}$ Relative contribution of the predictors $X_{17}$ (Lysine), $X_{5}$ (Histedine), and $X_{9}$ (Proline) to $R^{2}$ are $14.82,18.08$, and $10.71 \%$, respectively.

e Relative contribution of the predictors $X_{4}$ (Glycine) and $X_{2}$ (Glutamic) to $R^{2}$ are 17.45 and $13.67 \%$, respectively.

Table 8. Correlation between horizontal resistance of cotton genotypes to four isolates of FOV and amino acid content of the genotype seeds.

\begin{tabular}{llll}
\hline Amino acid & $\mathbf{r}^{\mathbf{a}}$ & Amino acid & $\mathbf{r}$ \\
\hline Aspartic & 0.021 & Tyrosine & 0.260 \\
Glutamic & -0.135 & Valine & 0.187 \\
Serine & 0.015 & Methionine & 0.097 \\
Glycine & 0.309 & Cystine & 0.113 \\
Histedine & 0.305 & Isoluecine & 0.151 \\
Arginine & -0.026 & Luecine & -0.022 \\
Therionine & 0.172 & Phenylalanine & -0.096 \\
Alanine & -0.190 & Lysine & -0.249 \\
Proline & 0.333 & &
\end{tabular}

a Pearson correlation coefficient (r), which measures the degree of association between horizontal resistance of the tested genotypes and concentration of the designated amino acid.

Table 9. Stepwise regression model that describes the relationship between horizontal resistance $(Y)$ of cotton genotypes to four isolates of FOV and amino acid content (Xs) of the genotype seeds.

\begin{tabular}{ccc}
\hline Stepwise linear regression model & $\begin{array}{c}\text { Coefficient of } \\
\text { determination } \\
\left(\mathbf{R}^{2}\right)\end{array}$ & F. value \\
\hline $\mathrm{Y}=3.61+545.48 \mathbf{X}_{9}+558.08 \mathbf{X}_{5}-604.82 \mathbf{X}_{17}$ & $36.36 \%$ & $3.05 \mathrm{x}$ \\
\hline
\end{tabular}

${ }^{a} F$. value is significant at $p<0.10(x)$.

b Relative contribution of the predictors $X_{9}$ (Proline), $X_{5}$ (Histedine), and $X_{17}$ (Lysine) to $R^{2}$ are $11.11,14.18$, and $11.07 \%$, respectively. 


\section{REFERENCES}

Aly, A.A., H.A. Eisa, M.T.M. Mansour, S.M.E. Zayed, and M.R. Omar. 2000 Resistance to Fusarium wilt disease in families of some commercial cotton cultivars. pp. 375-384. In: Proc. 9 $9^{\text {th }}$ Cong. Egypt. Phytopathol. Soc., Giza.

Armstrong, G.M. and Joanne K. Armstrong. 1978. Formae speciales and races of Fusarium oxysporum causing wilts of Cucurbitaceae. Phytopathology 68: 19-28.

Bakry, M.A., A.H. Sakre, O.A. Kassab, and R.H. Rizk. 1958. Infection of some cotton varieties with Fusarium and the possibility of the existence of strains of the fungus. Proc. $2^{\text {nd }}$ Cotton Conf. (In Arabic).

Bhattacharya, A. and P. Shukla. 1996. Effect of Erysiphe polygoni. D.C. infection on activation of some hydrolytic enzymes and their metabolites in Pisum sativum L. leaves. Legume Research 19: 133 137.

Cohen, S.A., M. Mewyes, and T.L. Travin. 1989. The pico tag method. In: A Manual of Advanced Techniques for Amino Acid Analysis. Millipore, USA.

El-Hamalawi, Z.A. and J.A. Menge. 1995. Seasonal fluctuations in the extent of colonization of avocado plants by the stem canker pathogen Phytophthora citricola. Journal of the American Society for Horticultural Science 120:157-162.

Liu, F. 1997. Protein and amino acid contents in cotton seedlings as related to their resistance to Fusarium wilt (Fusarium oxysporum f.sp. vasinfectum). Journal of Southwest Agricultural University 19:161-164.

Mahakul, A.K., M. Anuradha, and B.R. Maity. 1996. Formation and germination of hyphal chlamydospores in Fusarium oxysporum f.sp. ciceri, the vascular wilt pathogen on chickpea. Environment and Ecology 14:699703.

Mehta, A., P. Mehta, and S. Chopra. 1991. Effect of various nitrogenous sources on the production of pectolytic and cellulolytic enzymes by Fusarium oxysporum and F. moniliforme. Zentralblatt Fur Mikrobiologie 146:393-398.

Omokolo, N.D. and T. Boudjeko. 2005. Comparative analysis of alterations in carbohydrates, amino acids, phenols, and lignin in roots of three cultivars of Xanthosoma sagittifolium infected by Pythium myriotylum. South African Journal of Botany 71:432-440.

Omokolo, N.D., D.J. Nankeu, N. Niemenak, and P.F. Djocgoue. 2002. Analysis of amino acids and carbohydrates in the cortex of nine clones of Theobroma cacao L. in relation to their susceptibility to Phytophthora megakarya Bra. And Grif. Crop Protection 21:395-402.

Osman, Eman, A.M. 1996. Studies on the interrelationship among some Fusarium species with special reference to their pathogenicity on cotton. Ph.D. Thesis, Cairo Univ., Cairo. 125p.

Podleckis, E.V., C.R. Curtis, and H.E. Heggestad. 1984. Peroxidase enzyme markers for ozone sensitivity in sweet corn. Phytopathology 74: 572-577. 
Pundir, C.S., O.M. Singh, and H.C. Verma. 1991. Effects of Fusarium wilt on free amino acids in the progeny of healthy and infected lentil. Indian Phytopathology 43:580-582.

Salgado, M.O., H.F. Schwartz, and M.A. Pastor Corrales. 1994. Resistance to Fusarium oxysporum f.sp. phaseoli in tepary beans (Phaseolus acutifolius). Plant Disease 78: 357-360.

Vanderplank, J.E. 1984. "Disease Resistance in Plants", $2^{\text {nd }}$ Ed. Academic Press, Orlando, Florida. 194p.

Yang, Z., R. Wang, and Y. Gao. 1995. Effects of root effusion of different cotton varieties on Fusarium oxysporum f.sp. vasinfectum. Scientia Agricultura Sinica 28:87-88.

Zink, F.W., W.D. Guber, and R.G. Grogan. 1983. Reaction of muskmelon germplasm to inoculation with Fusarium oxysporum f.sp. melonis race 2. Plant Disease 67: 1251-1255.

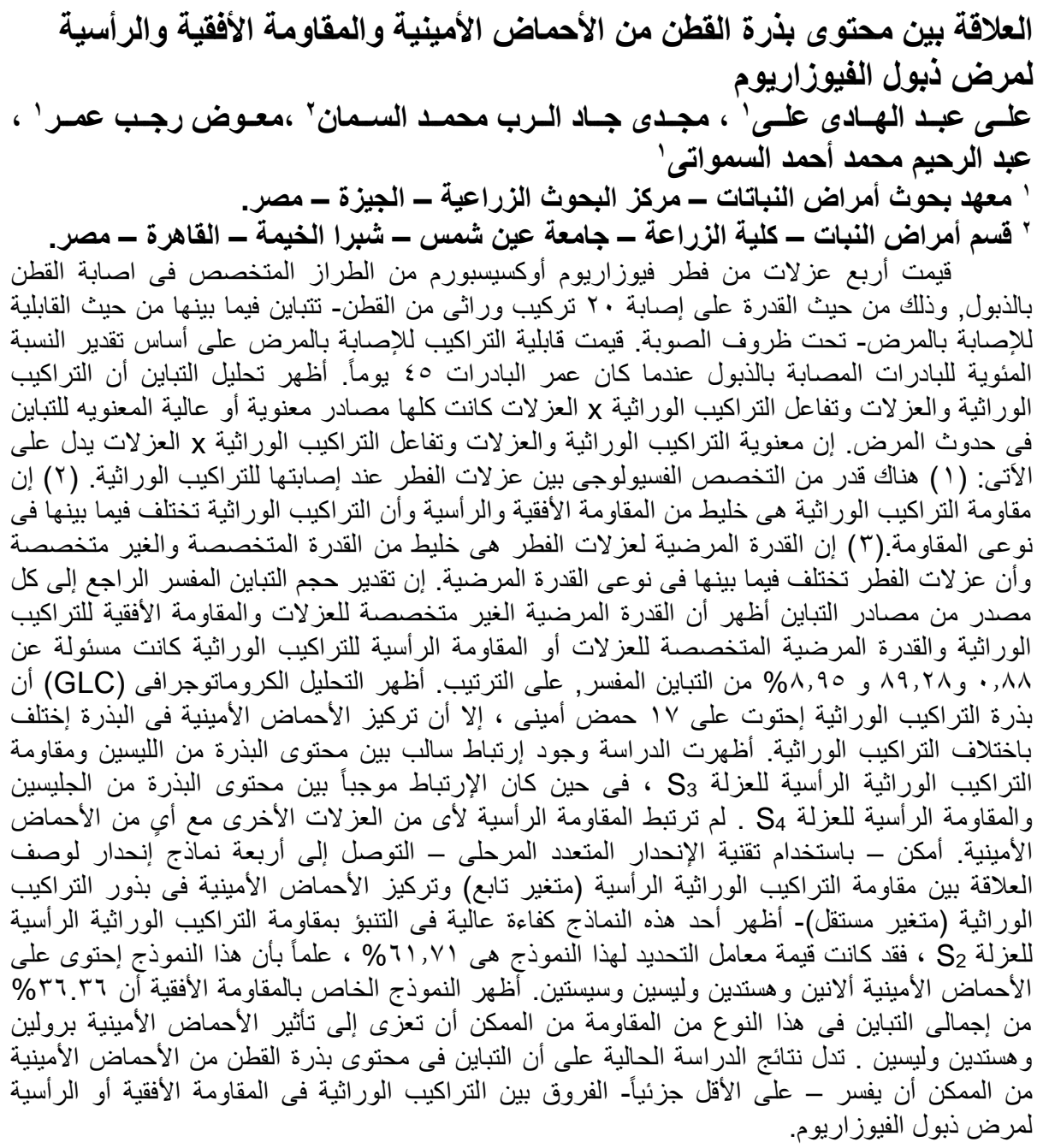

